PAPER

\title{
Biological activity of interferon betas in patients with multiple sclerosis is affected by treatment regimen and neutralising antibodies
}

\author{
A Bertolotto, A Sala, S Malucchi, F Marnetto, M Caldano, A Di Sapio, M Capobianco, F Gilli
}

See Editorial Commentary, p 1234

J Neurol Neurosurg Psychiatry 2004;75:1294-1299. doi: 10.1136/jnnp.2004.037259

See end of article for authors' affiliations

Correspondence to:

Dr A Bertolotto, Centro Riferimento Regionale Sclerosi Multipla (CReSM) and Neurobiologia Clinica, ASO S. Luigi Gonzaga, Regione Gonzole 10, 10043, Orbassano, Torino, Italy; sclerosi.multipla@ sanluigi.piemonte.it

Received 20 January 2004 In revised form 21 April 2004 Accepted 14 May 2004
Background: MxA gene expression is one of the most appropriate markers of biological activity of exogenous interferon (IFN) beta.

Methods: We quantified MxA mRNA for five consecutive days in 62 patients treated with IFN beta (16, Avonex; 10, Betaferon; 24, Rebif 22; 12, Rebif 44), by quantitative-competitive polymerase chain reaction. Every three months, IFN beta induced neutralising antibodies (NAbs) were evaluated in sera using a cytopathic effect assay.

Results: Two categories of patients were identified: one group (49/62) had a sharp post-injection increase in MxA expression (defined as "IFN beta biological responder"), whereas the other group (13/62) had no MxA induction after IFN beta administrations (defined as "IFN beta biological non-responder"). In 11 / 13 biological non-responders, the persistent presence of NAbs correlated with abolished biological activity, independently of treatment regimen. The two remaining IFN beta biological non-responders were $\mathrm{NAb}-$. Among the 49 IFN beta biological responders, biological activity was comparable between the four preparations on day 2 and 3 ( +12 and +36 hours post-injection), but it was greater in Betaferon and both Rebif preparations on day 1, 4, and 5. In biological responders treated three times a week, only $82 \%$ (59/72) of injections were considered effective, compared with 100\% (13/13) of Avonex injections.

Conclusion: Our results suggest that an optimal IFN beta regimen is not yet available: Avonex, given once a week, shows lower cumulative biological activity. On the other hand, both Betaferon and Rebif, given three times a week, show $18 \%$ biologically ineffective injections and higher risk of developing NAbs, which abolish biological activity.
$\mathrm{T}$ he efficacy of interferon (IFN) beta in the treatment of multiple sclerosis (MS) has been demonstrated in several trials. ${ }^{1-7}$ However, in some patients with MS this therapy is less effective, and they are considered non-responders. In some of these patients the development of anti-IFN beta neutralising antibodies (NAbs) has been observed. ${ }^{8}$ NAbs can interfere with the receptor binding sequence of IFN beta, inhibiting biological activity ${ }^{10-12}$ and therapeutic action. ${ }^{6} 8913$

Biological activity can be estimated by measuring markers of IFN beta activity, which are specific IFN induced proteins that have been demonstrated to peak after IFN beta injections. ${ }^{14-16}$ Of the usual biological markers of IFN beta in peripheral blood (myxovirus resistance protein A (MxA), $2^{\prime}-5^{\prime}$ oligoadenylate synthetase (OAS), $\beta 2$-microglobulin), MxA has a dose dependent specificity for type I IFNs, but not for IFN gamma. ${ }^{17}$ At present, MxA is thought to be an appropriate marker to measure the biological activity of exogenous IFN beta in patients with MS. More specifically, as mRNA has a shorter half-life than the protein, ${ }^{18}$ the measurement of a specific transcript offers a better measure of the biological activity of IFN beta. ${ }^{19} 20$

We measured MxA mRNA using a quantitative-competitive polymerase chain reaction (qc-PCR) technique shown to be precise, accurate, and sensitive to a level of $1 \mathrm{fgMxA} /$ pgGAPDH. ${ }^{19}{ }^{21}$ This method of quantification allowed us to determine and analyse fluctuations of MxA expression during five days of treatment, to evaluate the biological activity of IFN beta in parallel with the development of NAbs, and to compare the biological response to IFN beta in patients with MS treated once a week with Avonex or three times a week with either Betaferon or Rebif (Rebif 22 and Rebif 44).

\section{PATIENTS AND METHODS}

\section{Patients}

Blood samples were obtained from a total of 62 patients with MS (22 men and 40 women) who received treatment with recombinant IFN beta. Of these, 16 received IFN beta-la (Avonex; Biogen, Cambridge, USA) 30 micrograms intramuscularly (IM) once a week, 36 received IFN beta- la (Rebif; Serono, Basel, Switzerland), either 22 micrograms $(n=24)$ or 44 micrograms $(n=12)$ subcutaneously $(\mathrm{SC})$ three times a week, and 10 received IFN beta-lb (Betaferon; Schering, Berlin, Germany) 250 micrograms SC three times a week. The mean duration of therapy was 20 (SD 17) months (range 3-60 months) (table 1).

Patients were not randomised and enrolled retrospectively. Eligibility criteria included a diagnosis of MS according to the McDonald criteria, ${ }^{22}$ relapsing-remitting (RR) clinical course, Expanded Disability Status Scale (EDSS) score 0-6.5, and informed consent. All patients included were clinically inactive and steroid free in the three months preceding the enrolment. Exclusion criteria included significant other medical illnesses, previous switch in type of IFN beta treatment, and prior immunosuppressive therapy with cytotoxic activity.

\section{Study design}

Eligible patients had been under treatment for at least three months prior to the study and had been screened for the

Abbreviations: AUC, area under the concentration time curve; EDSS, Expanded Disability Status Scale; IFN, interferon; MS, multiple sclerosis; MxA, myxovirus resistance protein $A ; N A b s$, neutralising antibodies; OAS, oligoadenylate synthetase; PBMC, peripheral blood mononuclear cell; TRU, tenfold reduction unit 
Table 1 Demographic and clinical characteristics of 62 patients with MS treated with four different interferon beta regimens

\begin{tabular}{|c|c|c|c|c|c|}
\hline & $\begin{array}{l}\text { Avonex } \\
(n=16)\end{array}$ & $\begin{array}{l}\text { Betaferon } \\
(n=10)\end{array}$ & $\begin{array}{l}\text { Rebif } 22 \\
(n=24)\end{array}$ & $\begin{array}{l}\text { Rebif } 44 \\
(n=12)\end{array}$ & $\begin{array}{l}\text { Total } \\
(n=62)\end{array}$ \\
\hline $\operatorname{Sex}(M / F)$ & $5 / 11$ & $4 / 6$ & $7 / 17$ & $6 / 6$ & $22 / 40$ \\
\hline Body mass* & $\begin{array}{l}1.763(0.14), \\
1.51-1.97\end{array}$ & $\begin{array}{l}1.724(0.14), \\
1.55-1.94\end{array}$ & $\begin{array}{l}1.753(0.17) \\
1.50-2.10\end{array}$ & $\begin{array}{l}1.764(0.11), \\
1.59-1.95\end{array}$ & $\begin{array}{l}1.753(0.14) \\
1.50-2.10\end{array}$ \\
\hline Duration of disease ${ }^{*}$ & $8.0(4.6), 1-18$ & $10.0(6.1), 4-26$ & $8.4(5.1), 1-2$ & $6.7(4.8), 1-18$ & $8.0(5.2), 1-26$ \\
\hline Months of therapy* & $16(7), 5-29$ & $35(20), 4-60$ & $21(18), 3-60$ & $11(10) \pm, 3-36$ & $20(17), 3-60$ \\
\hline EDSS* & $2.0(1.0), 0-4.0$ & $2.0(1.0), 1.0-6.5$ & $2.0(1.0), 0-5.0$ & $2.0(1.0), 0-5.0$ & $2.0(1.5), 0-6.5$ \\
\hline \multicolumn{6}{|l|}{ Nab status $†$} \\
\hline $\mathrm{NAb}-$ & $14(88)$ & $6(60)$ & $17(71)$ & $10(83)$ & $47(76)$ \\
\hline Persistent NAb+ & $2(12)$ & $3(30)$ & $5(21)$ & $2(17)$ & 12 (19) \\
\hline Isolated NAb+ & - & $1(10)$ & $2(8)$ & - & $3(5)$ \\
\hline \multicolumn{6}{|c|}{$\begin{array}{l}\text { *Mean (SD), range. } \\
\text { †Number (\%). } \\
\text { †Since Rebif } 44 \text { was more recently approved for the treatment of MS than Avonex, Betaferon, and Rebif } 22 \text {, the duration of treatment with Rebif } 44 \text { compared with } \\
\text { the other three treatment regimens was statistically different. } \\
\text { EDSS, Expanded Disability Status Scale; F, female; M, male; MS, multiple sclerosis. }\end{array}$} \\
\hline
\end{tabular}

presence of IFN beta induced NAbs before and every three months, as previously described. ${ }^{23} 24$

MxA mRNA was assessed every morning from day 1 to day 5. All patients had their injections synchronised for the study; as a consequence Avonex was always administered once a week between $8 \mathrm{pm}$ and $10 \mathrm{pm}$ of day 1 , whereas Betaferon, Rebif 22, and Rebif 44 were injected between 8 pm and $10 \mathrm{pm}$ of day 1 and day 3. Blood samples were taken every morning between $8 \mathrm{am}$ and $10 \mathrm{am}$. On day 1 NAbs were also measured.

\section{Quantification of MxA mRNA}

MxA mRNA was quantified according to our previously published protocol. ${ }^{1921}$ Briefly, peripheral blood mononuclear cells (PBMCs) were separated on a Ficoll-Hypaque (Pharmacia, Uppsala, Sweden) density gradient and total RNA was extracted using RNAwiz reagent, following the manufacturer's instructions (Ambion, Austin, TX). Complementary DNA (cDNA) was then prepared, using 10 $\mathrm{mM}$ of random hexamer primers (Perkin Elmer, Norwalk, CT) and $100 \mathrm{U}$ of Moloney murine leukaemia virus reverse transcriptase (Gibco Laboratories, Grand Island, NY). For the qc-PCR) reaction two competitor cDNA fragments (Co-MxA and co-glyceraldehyde phosphate dehydrogenase (GAPDH)) were generated and co-amplified with target cDNA. ${ }^{19}$ PCR amplification products were then resolved following separation by $2 \%$ agarose gel electrophoresis. Bands were visualised by EtdBr staining and quantified by densitometric scanning of the gel using a GelDoc 1000 UV fluorescent system (BioRad, Richmond, CA).

The ratios between competitors and target cDNA were evaluated as ratios between bands values, taking as ratio $=1$ an amount of starting targets (MxA or GAPDH) equal to the amount of each competitor. ${ }^{19}$ The MxA mRNA levels, expressed as fgMxA/pgGAPDH, were normalised using GAPDH as housekeeping gene, to avoid differences due to possible RNA degradation/contamination or different reverse transcription efficiency.

\section{Evaluation of neutralising antibodies}

NAbs were measured with a bioassay based on the cytopathic effect (CPE) of encephalomyocarditis virus (EMC) (CPE assay) on human lung carcinoma cells (A549). ${ }^{23} 24$ Serum samples were diluted, mixed with one of the three IFN beta preparations at a final concentration of $10 \mathrm{IU} / \mathrm{ml}$, and added overnight to monolayers of A549 cells in 96 well plates. Cells were then infected with EMC murine virus and viable cells were quantified 24 hours later by staining with crystal violet in $20 \%$ ethanol. The dye taken up by the cells was eluted with $33 \%$ acetic acid and its absorbance was measured in a densitometer at $620 \mathrm{~nm}$. The neutralisation titre of a serum sample was calculated according to Kawade's formula ${ }^{25}$ and expressed in tenfold reduction unit (TRU). ${ }^{26}$ A level of $\geqslant 20$ TRU was considered as the threshold for positivity.

Three categories of patients were identified based on NAbs: $\mathrm{NAb}$ negative (NAb-) patients had no positive samples during follow up; persistent $\mathrm{NAb}$ positive $(\mathrm{NAb}+)$ patients had at least two consecutive samples positive for NAbs; and isolated NAb+ patients had a single $\mathrm{NAb}+$ sample or had sporadic positivity during follow up.

\section{Statistical analysis}

The data was statistically analysed using GraphPad Prism program version 4.0 (GraphPad Software Inc., San Diego, $\mathrm{CA}$ ). The area under the concentration time curve (AUC) was calculated using the trapezoid summation after adjusting for baseline values. Non-parametric statistical tests were used according to the parameters analysed (Mann-Whitney test and Wilcoxon's test). Differences were considered significant when $\mathrm{p}<0.05$.

\section{RESULTS}

\section{Patients}

Table 1 shows the baseline demographic and clinical characteristics of the study patients. There were no significant differences between the groups with regard to demographic or clinical characteristics, except for the duration of treatment with Rebif 44, which was shorter compared with the other three treatment regimens (Rebif $22 v$ Rebif 44, $\mathrm{p}=0.0456$; Avonex $v$ Rebif 44, $\mathrm{p}=0.0318$; Betaferon $v$ Rebif $44, p=0.0051)$. Most of the patients $(65 \%)$ were women and the mean age was 35.4 years.

\section{Neutralising antibody status}

No patient was positive for NAbs at baseline. Of the 12 persistent $\mathrm{NAb}+$ patients, nine were evaluated as positive on day 1 of the study and had mean NAb titres $\geqslant 45$ TRU; two patients were negative on day 1 and had always had NAb titres $<45$ TRU in previous NAbs tests. One patient was positive on day 1 and presented previous and present NAb titres $<45$ TRU.

The patients were not randomised, but retrospectively included, since the present study was not conducted to determine the incidence and prevalence of NAbs in serum samples from patients with MS who were treated with Betaferon, Avonex, Rebif 22, or Rebif 44. Hence a direct comparison of the percentage of NAbs+ and Nabs- patients reported in this study is not possible. 
IFN beta biological responders and non-responders In a previous report, we examined the MxA gene expression in PBMCs from 99 untreated patients with MS and we calculated an upper threshold of normal as mean baseline expression+3 SD $=132 \mathrm{fgMxA} /$ pgGAPDH. ${ }^{13}$

Two categories of patients treated with IFN beta were identified based on MxA mRNA levels after IFN beta administration: IFN beta biological responders had at least one MxA mRNA value higher than the established threshold $(\geqslant 132 \mathrm{fgMxA} / \mathrm{pgGAPDH})$, and IFN beta biological nonresponders had MxA mRNA values lower than $132 \mathrm{fgMxA} /$ pgGAPDH during the whole study.

Based on the above threshold, 49/62 (79\%) patients were IFN beta biological responders, whereas the remaining 13/62 ( $21 \%)$ patients were IFN beta biological non-responders as MxA expression was unaffected by IFN beta administration.

Among the biological responders, 13 were treated with Avonex ( $81 \%$ of the patients treated with Avonex), 7 were treated with Betaferon (70\%), 19 were treated with Rebif 22 $(79 \%)$, and 10 were treated with Rebif 44 (83\%). Moreover, of the 49 IFN beta biological responders, 45 (92\%) patients were $\mathrm{NAb}-$, three patients were isolated $\mathrm{NAb}+$, and one patient was persistent $\mathrm{NAb}+$. However, the three isolated NAb+ and the single persistent $\mathrm{NAb}+$ patient presented NAbs titres $<45$ TRU during their follow up and were negative during the study.

Among the 13 IFN beta biological non-responders, 10 were found to be persistent $\mathrm{NAb}+$ and positive during the study, one was persistent $\mathrm{NAb}+$ and negative during the study, and two patients were NAb-.

\section{MxA expression and neutralising antibody status}

A comparison of MxA expression and NAb status showed that changes in MxA mRNA levels were greater in NAb- than in persistent NAb+ patients (fig 1). Such analysis was not possible for isolated $\mathrm{NAb+}$, because they were too few in number.

Not unexpectedly, abolished MxA gene expression was more commonly found in patients with high NAb titres $(\geqslant 45$ TRU) than in patients with low $(<45$ TRU) NAb titres: all patients $(100 \%)$ with NAb titres $\geqslant 45$ TRU showed no biological activity, as indicated by MxA mRNA levels $<132$ fgMxA/pgGAPDH during the whole study (fig 1). Of the three remaining persistent NAb+ patients with NAb titres

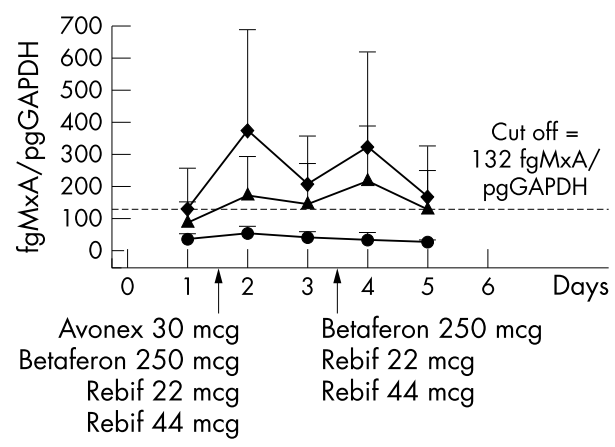

Figure 1 Average profiles of $M x A$ gene expression in peripheral blood mononuclear cells of 62 patients with multiple sclerosis treated with interferon beta, subdivided by neutralising antibody (NAb) status: filled diamonds, NAb- patients ( $n=47$ ); filled triangles, persistent NAb+ patients with previous and present NAb titres $<45$ TRU $(n=3)$; and filled circles, persistent $N A b+$ patients with previous and present NAb titres $\geqslant 45$ TRU $(n=9)$. Isolated NAb+ were not considered because of the small number of patients. Mean and unidirectional standard deviation values are indicated and the dotted line represents the threshold level. $\mathrm{mcg}$, micrograms.
$<45$ TRU, two subjects showed no biological activity, but one patient showed significant increases in MxA mRNA.

When the AUCs were compared, the total augmentation of MxA mRNA was fourfold greater in the NAb- group than in persistent $\mathrm{NAb}+(\mathrm{p}<0.0001)$.

\section{Comparison of the biological activity of the four interferon beta preparations}

Following the administration of IFN beta in biological responders, MxA mRNA concentrations peaked at 12 hours and then declined to baseline levels. ${ }^{13}{ }^{19}$ As expected, MxA mRNA levels in patients given Avonex were lowest on day 1 , peaked on day $2(+12$ hours after injection) and then decreased in the following days (fig 2A). No such decrease was seen with Betaferon or Rebif (Rebif 22 and Rebif 44) because, for both preparations, a booster was given three times a week rather than once a week. In particular, the average profiles of MxA expression, in patients treated with both Betaferon and Rebif, showed a second peak of expression on day $4,+12$ hours after the second IFN beta injection (fig 2B-D).

MxA expression for both Betaferon and Rebif groups was statistically greater than that for the Avonex group on day 1 (all $\mathrm{p} \leqslant 0.038$ ), 4 (all $\mathrm{p} \leqslant 0.045$ ), and 5 (all $\mathrm{p} \leqslant 0.044$ ) (table 2 ). On the other hand, differences of MxA mRNA levels among the four preparations of IFN beta were not significant on day 2 and $3(+12$ and +36 hours after the first IFN beta injection) (all $p \geqslant 0.077$ ) (table 2). Interestingly, no differences in the MxA expression were found between Rebif 22 and Rebif 44 during the five days of treatment (all $\mathrm{p} \geqslant 0.24$ ) (table 2).

There were no statistical differences among the MxA mRNA levels induced at each time point in persistent NAb+ patients treated with Avonex versus Betaferon, Rebif 22, and Rebif 44 (all $p \geqslant 0.12$ ) (fig 2).

Although this study analysed only five treatment days and did not consider the effect of the third weekly injection of Betaferon and both Rebif preparations, the MxA mRNA AUC values approached statistical significance for both Rebif preparations and Betaferon versus Avonex (0.058 $\geqslant p \geqslant 0.071)$.

\section{Biologically effective injections}

The profiles of the MxA concentration time curve were similar in all biological responders under treatment with Avonex. On the other hand, some subjects treated three times a week with either Betaferon or Rebif presented an unexpected profile, as MxA expression did not increase after one of the two injections considered. To examine this phenomenon, we evaluated the biological efficacy of every injection separately: injections were considered "biologically effective" when they induced MxA mRNA levels higher than the established threshold ( $132 \mathrm{fgMxA} / \mathrm{pgGAPDH})$.

Among the 49 biological responders, 13 were treated once a week, and 36 were treated three times a week $(7$, Betaferon; 19, Rebif 22; 10, Rebif 44). Of these 36 patients, 13 (36\%) presented a single "biologically effective" injection, instead of two: 2/7 (29\%) were treated with Betaferon, 7/19 (37\%) were treated with Rebif 22, and 4/10 (40\%) were treated with Rebif 44. Ineffective injections were detected indiscriminately after both the first and second injection. As a whole, in biological responders treated three times a week, only $82 \%$ injections (59/72) were "biologically effective", compared with $100 \%$ (13/13) of Avonex injections.

\section{DISCUSSION}

Four IFN beta preparations are presently used in the treatment of MS: Avonex, Betaferon, Rebif 22, and Rebif 44. The differences among the four preparations are in their biochemical structure, dose, dosing frequency, route of administration, and vehicle. Despite these differences, 

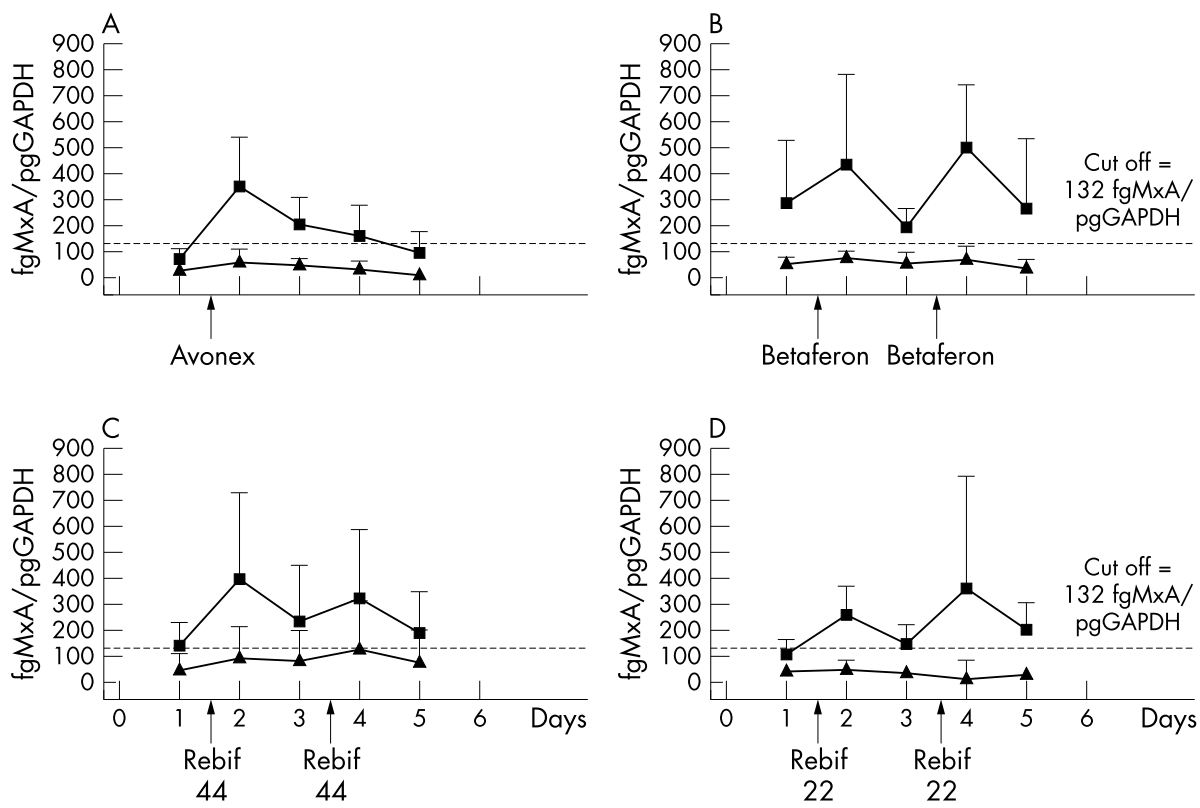

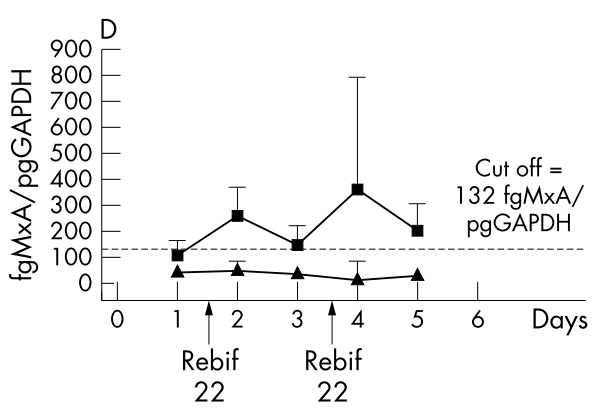

Figure 2 Average profiles of $M x A$ gene expression in peripheral blood mononuclear cells of 62 patients with multiple sclerosis treated with (A) Avonex 30 micrograms/week, (B) Betaferon 250 micrograms $/ 3 \times$ week, and Rebif either (C) 44 micrograms/ $3 \times$ week or (D) 22 micrograms/ $3 \times$ week. Patients were divided according to the neutralising antibody status: filled squares, NAb- patients; filled triangles, persistent NAb+. Isolated NAb+ status was not considered because of the paucity of the patients. Mean and unidirectional standard deviation values are indicated and the dotted line represents the threshold level. significant therapeutic effects were observed with each preparation. $^{1-7}$ However, the optimal dosing regimen for IFN beta therapy in this indication is still under debate. Moreover, several studies have demonstrated different degrees of immunogenicity, probably due to one or more of the above mentioned differences. ${ }^{9}{ }^{1327}$

To compare the degree and duration of modulation of the biological response induced by the four IFN beta preparations, in the present study we evaluated in vivo changes in MxA gene expression in patients with MS during five days of treatment. As far as we know, such temporal characterisation of biological activity has not been described previously. In the other investigations in which IFN beta biological activity was studied for several consecutive days, the following topics were analysed: (a) healthy volunteers treated with IFN beta rather than treated patients with $\mathrm{MS}^{28}(b)$ study of only one ${ }^{28}$ or two ${ }^{16}$ preparations instead of four, and $(c)$ data obtained ex vivo instead of in vivo. ${ }^{28}$ Moreover, the authors measured protein markers such as $\beta 2$-microglobulin, OAS, and MxA. ${ }^{16} 28$ Although these proteins are considered as classic markers of the biological activity of IFN beta, they are characterised by slow decay. ${ }^{14-16} 28$ Therefore, although the protein quantification using methods such as enzyme-linked immunosorbent assay (ELISA) ${ }^{10}{ }^{18}$ is simpler than the measurement of the specific transcript, we preferred mRNA quantification because mRNA has a shorter half-life than the protein, ${ }^{18}$ and its level reflects biological activity of every single injection allowing the detection of small fluctuations in expression.

Table 2 MxA mRNA expression in patients negative for neutralising antibodies during five days of treatment

\begin{tabular}{lllll}
\hline & $\begin{array}{l}\text { Avonex } \\
(\mathbf{n}=14)\end{array}$ & $\begin{array}{l}\text { Betaferon } \\
(\mathrm{n}=6)\end{array}$ & $\begin{array}{l}\text { Rebif 22 } \\
(\mathbf{n}=17)\end{array}$ & $\begin{array}{l}\text { Rebif 44 } \\
(\mathrm{n}=10)\end{array}$ \\
\hline Day 1 & $69(43)^{*}$ & $284(243)$ & $142(88)$ & $109(57)$ \\
Day 2 & $351(193)$ & $429(352)$ & $397(331)$ & $258(112)$ \\
Day 3 & $206(102)$ & $189(76)$ & $235(218)$ & $147(74)$ \\
Day 4 & $159(122)^{*}$ & $498(242)$ & $321(264)$ & $360(431)$ \\
Day 5 & $95(83)^{*}$ & $261(272)$ & $191(160)$ & $201(110)$ \\
\hline
\end{tabular}

Values are mean (SD) $\mathrm{fg} M \times \mathrm{A} / \mathrm{pg} G \mathrm{APDH}$.

*Statistical difference was found between the MxA mRNA levels induced by Avonex versus Betaferon, Rebif 22, and Rebif 44 on day 1,4 , and 5 . No difference was found on day 2 (+12 hours after the first injection) and day 3 (+36 hours).
In the present study, two categories of patients were identified based on MxA mRNA induction: IFN beta biological non-responders and IFN beta biological responders.

As previously demonstrated, ${ }^{12}$ the lack of biological activity correlated with both higher NAb titres and persistent presence of NAb. Under these conditions, IFN beta injections always failed to increase MxA mRNA levels independently of dose or dosing frequency of the treatment. On the other hand, the profiles of MxA AUCs in patients presenting persistently low NAbs titres ( $<45$ TRU) show a MxA induction, although at significantly lower levels (fig 1). This could imply that low NAbs titres can be overcome by increasing the dose of IFN beta, whereas in the presence of higher NAbs titres, the biological response to IFN beta is always abolished, even by higher doses and dosing frequency of the treatment.

Analysis of MxA mRNA levels in IFN beta biological responders clearly demonstrated higher biological responses in patients treated three times a week instead of once a week. The cumulative biological activities, as measured by AUC, approached statistical significance, although only two out of the three weekly injections were considered in this study. The third weekly injection influenced the level of MxA mRNA on day $1(+156$ hours for patients treated with Avonex and +60 hours for patients treated with Betaferon and the two Rebifs) as it was significantly higher in patients treated with Betaferon and the Rebifs compared with those treated with Avonex.

In addition, in IFN beta biological responders, the profiles of MxA concentration time curves demonstrate that the IFN signalling pathway and specific cell surface receptors can be stimulated more than once a week. However, the use of a three times a week dosing schedule induces $18 \%$ biologically "ineffective" injections, identified by the absence of a clearly detectable biological activity. Indeed, MxA increase after every IFN beta injection was observed only in $64 \%$ of responder patients treated three times a week compared with $100 \%$ responder patients treated once weekly. The remaining $36 \%$ of responder patients treated three times a week, failed to show increased MxA expression after one of the two injections. This phenomenon could be due to noncompliance, however, this seems unlikely as a small increase in MxA gene expression was observed after a few "ineffective" injections. Moreover, all patients treated with Avonex 
showed increase of MxA mRNA level after their single injection. On the other hand, the absence, or greatly reduced, MxA induction could have a biological basis. Therefore, it seems to be more likely that PBMCs of patients treated with IFN beta, undergo a process of desensitisation in response to repeated exposure to the cytokine. Accordingly, recently it has been observed that in vitro $\mathrm{T}$ cells become desensitised as a result of persistent IFN beta-la stimulation, regaining full responsiveness to treatment by 168 hours. ${ }^{29}$

Despite clear evidence of higher biological response in patients treated three times a week, it is unclear whether this difference is clinically relevant, as the lower biological activity of Avonex may be counterbalanced by its lower incidence of $\mathrm{NAb}$ induction observed in all therapeutic trials ${ }^{68913}$ and in longitudinal comparisons between the different types of IFN beta. ${ }^{27}{ }^{30}$ Moreover, it should be taken into consideration that a higher cumulative biological activity does not necessarily induce greater clinical efficacy. Indeed, clinical efficacy relates to half-life of induced molecules and/or modifications of cell populations with therapeutic action. Several lines of evidence point to the important role of the up/downregulation of cytokines and chemokines, ${ }^{28}{ }^{31-33}$ with fast induction and short half-life. ${ }^{28}$ Conversely, IFN beta also induces longlasting effects such as up/downregulation of other cytokines, ${ }^{31}$ increases in NK cells functional activity, ${ }^{34}$ development of different cell subsets, ${ }^{35}$ or downregulation of matrix metalloproteinases. ${ }^{36}$ Consequently, these effects, which are maintained for a week or more, require less frequent administrations of the drug. Anyway, therapeutic differences among the four IFN beta regimens can only be demonstrated by head to head clinical trials that have to last some years to take into consideration the delayed negative effects of NAbs. ${ }^{13}$

In conclusion the results of the present study demonstrate that an optimal IFN beta regimen is not yet available: Avonex, given once a week, shows significantly lower cumulative biological activity, but significantly lower incidence of NAbs, compared with both Betaferon and Rebif. ${ }^{1327}{ }^{30}$ On the other hand both Betaferon and Rebif (Rebif 22 and 44) given three times a week, show greater cumulative biological activity but higher risk of development of NAbs, ${ }^{13} 2730$ which abrogate IFN beta therapeutic action. ${ }^{6}{ }^{13} 36$ Hence, to tailor the best treatment in both patients with newly diagnosed MS and those already receiving treatment, the neurologist must carefully consider the results of clinical trials, the pharmacokinetic data, the risk of lost of therapeutic efficacy due to the development of NAbs, and the peculiar clinical and prognostic characteristics of each patient.

\section{ACKNOWLEDGEMENTS}

We thank Rita Guerrieri, Marina Panealbo, and Angela Zaccaria for nursing assistance, as well as Anna Messina for her excellent administrative support.

\footnotetext{
Authors' affiliations

A Bertolotto, A Sala, S Malucchi, F Marnetto, M Caldano, A Di Sapio, M Capobianco, F Gilli, Centro di Riferimento Regionale per la Sclerosi Multipla (CReSM) and Neurobiologia Clinica, ASO S. Luigi Gonzaga, Orbassano, Torino, Italy

This work was supported by Fondazione per la Ricerca Biomedica ONLUS and by Cavalieri Ottolenghi Foundation.

Competing interests: $A B, S M, M C$, and $A D S$ have been reimbursed by Farmades, Serono, and Dompè Biotech for attending several conferences; $A B$ received fees for lectures by Serono, Dompè Biotech and Biogen; $A B$ received funds for research and for staff members from Serono and Dompè Biotech. Farmades is the Italian distributor of Betaferon; Serono is the manufacturer of Rebif, Biogen of Avonex and Dompè Biotech is the Italian distributor of Avonex. The other authors have nothing to declare.
}

\section{REFERENCES}

1 IFN beta Multiple Sclerosis Study Group. Interferon beta-1b is effective in relapsing-remitting multiple sclerosis: clinical results of a multi-center randomized, double-blind, placebo controlled trial. Neurology 1993;43:655-61.

2 The IFN $\beta$ Multiple Sclerosis Study Group and the University of British Columbia MS/MRI Analysis Group. Interferon beta-1b in the treatment of multiple sclerosis: final outcome of the randomized controlled trial. Neurology 1995;45:1277-85.

3 Jacobs LD, Cookfair DL, Rudick RA, et al. Intramuscular Interferon beta-1 a for disease progression in relapsing multiple sclerosis. Ann Neurol 1996;39:285-94

4 European Study Group of Interferon $\beta-1 b$ in Secondary Progressive MS. Placebo-controlled multicentre randomized trial of interferon $\beta-1 \mathrm{~b}$ in treatment of secondary progressive multiple sclerosis. Lancet 1998;352:1491-97.

5 Comi G, Filippi M, Barkhof $F$, et al. Effect of early interferon treatment on conversion to definite multiple sclerosis: a randomised study. Lancet 2001;357:1576-82

6 The PRISMS (Prevention of Relapses and Disability by Interferon- $\beta$-1a Subcutaneously in Multiple Sclerosis) Study Group, the University of British Columbia MS/MRI Analysis Group. PRISMS-4: long-term efficacy of interferon- $\beta-1$ a in relapsing MS, Neurology 2001;56:1628-36.

7 Jacobs LD, Beck RW, Simon JH, et al. Intramuscular Interferon Beta- la therapy initiated during a first demyelinating event in multiple sclerosis. N Engl J Med 2000;343:898-904.

8 The IFN $\beta$ Multiple Sclerosis Study Group and the University of British Columbia MS/MRI Analysis Group. Neutralizing antibodies during treatment of multiple sclerosis with interferon beta- $1 \mathrm{~b}$ : experience during the first three years. Neurology 1996:47:889-94.

9 Sorensen PS, Ross C, Clemmesen KM, et al. Clinical significance of neutralizing antibodies against interferon beta in patients with relapsingremitting multiple sclerosis. Lancet 2003;362:1 184-91.

10 Deisenhammer F, Reindel M, Harvey J, et al. Bioavailability of interferon beta $1 \mathrm{~b}$ in MS patients with and without neutralizing antibodies. Neurology 1999;52:1239-43.

11 Vallittu AM, Halminen M, Peltoniemi J, et al. Neutralizing antibodies reduce MxA protein induction in interferon-beta la-treated MS patients. Neurology 2002;58:1786-90.

12 Bertolotto A, Gilli F, Sala A, et al. Persistent neutralizing antibodies abolish the interferon $\beta$ bioavailability in MS patients. Neurology 2003;60:634-9.

13 Pachner AR. Anti-IFN $\beta$ antibodies in IFN $\beta$-treated MS patients. Neurology 2003;61(suppl 5):S1-S5.

14 Chiang J, Gloff CA, Yoshizawa CN, et al. Pharmacokinetics of recombinant human interferon- $\beta_{\text {ser }}$ in healthy volunteers and its effects on serum neopterin. Pharmacol Res 1993; 10:567-72.

15 Witt PL, Storer BE, Bryan GT, et al. Pharmacodynamics of biological response in vivo after single and multiple doses of interferon- $\beta$. J Immunother 1993;13:191-200.

16 Williams GJ, Witt PL. Comparative study of the pharmacodynamic and pharmacologic effects of Betaseron and Avonex ${ }^{T M}$. J Interferon Cytokine Res 1998; 18:967-75.

17 von Wussow P, Jakschies D, Hochkeppel HK, et al. The human intracellular $\mathrm{Mx}$-homologous protein is specifically induced by type I interferons. Eur J Immunol 1990;20:2015-19.

18 Kracke A, von Wussow P, Al-Masri AN, et al. Mx proteins in blood leukocytes for monitoring interferon beta-1b therapy in patients with MS. Neurology 2000;54:193-9.

19 Bertolotto A, Gilli F, Sala A, et al. Evaluation of bioavailability of three types of IFN $\beta$ in multiple sclerosis patients by a new quantitative-competitive-PCR method for MxA quantification. J Immunol Methods 2001;256:141-52.

20 Pachner AR, Bertolotto A, Deisenhammer F. Measurement of MxA mRNA or protein as a biomarker of IFN $\beta$ bioactivity: detection of antibody-mediated decreased bioactivity (ADB). Neurology 2003;61(suppl 5):S24-S26.

21 Gilli $F$, Sala A, Bancone C, et al. Evaluation of IFN $\alpha$ bioavailability by $M \times A$ mRNA in HCV patients. J Immunol Methods 2002;262:183-86.

22 McDonald WI, Compston A, Edan G, et al. Recommended diagnostic criteria for multiple sclerosis: guidelines from the international panel on the diagnosis of multiple sclerosis. Ann Neurol 2001;50:121-7.

23 Bertolotto A, Malucchi S, Milano E, et al. Interferon $\beta$ neutralizing antibodies in multiple sclerosis: neutralizing activity and cross-reactivity with three different preparations. Immunopharmacology 2000;48:95-100

24 Antonelli G, Bagnato F, Pozzilli C, et al. Development of neutralizing antibodies in patients with relapsing-remitting multiple sclerosis treated with IFN- $\beta 1$ la. J Interferon Cytokine Res 1998;18:345-50.

25 Kawade Y. Quantitation of neutralization of interferon by antibodies. Methods Enzymol 1986; 1 19:558-73

26 Grossberg SE, Kawade Y, Kohase M, et al. The neutralization of interferons by antibody. II. Neutralizing antibody unitage and its relationship to bioassay sensitivity: the tenfold reduction unit, J Interferon Cytokine Res 2001;21:743-55

27 Bertolotto A, Malucchi S, Sala A, et al. Differential effects of three interferon betas on neutralising antibodies in multiple sclerosis patients: a follow-up study in an independent laboratory. J Neurol Neurosurg Psychiatry 2002;73:148-53

28 Rothuizen LE, Buclin T, Spertini F, et al. Influence of interferon $\beta$-la dose frequency on PBMC cytokine secretion and biological effect markers. J Neuroimmunol 1999;99:131-41.

29 Dupont SA, Goelz S, Goyal J, et al. Mechanisms for regulation of cellular responsiveness to human IFN-beta la. J Interferon Cytokine Res 2002;22:491-501. 
30 Ross $C$, Clemmesen KM Svenson $M$, et al. Immunogenicity of interferon-beta in multiple sclerosis patients: influence of preparation, dosage, dose frequency, and route of administration. Ann Neurol 2000:48:706-12.

31 Rudick RA, Ransohoff RM, Lee JC, et al. In vivo effects of interferon beta- la on immunosuppressive cytokines and multiple sclerosis. Neurology 1998; 50: 1294-300

32 Weinstock-Guttman B, Ransohoff RM, Kinkel RP, et al. The interferons: biological effects, mechanisms of action, and use in multiple sclerosis. Ann Neurol 1995;37:7-15.
33 Arnason BGW, Dayal A, Qu ZX, et al. Mechanisms of action of interferon- $\beta$ in multiple sclerosis. Semin Immunopathol 1996;18:125-48.

34 Kastrukoff LF, Morgan NG, Zecchini D, et al. Natural killer cells in relapsing remitting MS: effects of treatment with interferon $\beta$-1b. Neurology 1999:52:351-9.

35 Paul WE, Sender RA. Lymphocyte responses and cytokines. Cell 1994;76:241-51

36 Gilli F, Bertolotto A, Sala A, et al. Neutralising antibodies against IFN- $\beta$ in MS: antagonisation of IFN- $\beta$ mediated suppression of MMPs. Brain 2004; 127(Pt 2):259-68.

\section{HISTORICAL NOTE}

\section{Cotugno and cerebrospinal fluid}

n 1761 Cotugno gave the first reliable account of ventricular and subarachnoid fluid. ${ }^{1}$ Until Cotugno, anatomists had found empty spaces around the brain and cord and thought that in life they were filled by vapour. Willis said the ventricles were empty spaces, or served the "vile duty of a sewer. In the dead they may be filled with water...if the serous fluid in the blood is too abundant.".2 Albrecht von Haller's famous textbook ${ }^{3}$ (at the same time as Cotugno's studies) describes:

\begin{abstract}
"As in the pericardium... a thin humour constantly exhales from the arteries into the ventricles of the brain and is constantly drawn back through the veins...so often the collected moisture turns into water and even distends the ventricles...A great abundance of water has been found in the ventricles of apoplectics, the soporose, convulsives, paralytics, and victims of epidemic fevers; hydrocephalus even more."
\end{abstract}

Cotugno studied 20 adult male bodies. He established the free circulation between the cranial and spinal dura of cerebrospinal fluid (sometimes referred to as liquor Cotunnii). His lucid description indicating its formation and absorption from blood vessels is contained in his work on sciatica. ${ }^{4}$

"Not only does this water contained in the tube of dura mater ensheathing the spinal marrow [cord] from the occiput to the os sacrum, surround the marrow constantly, but it also abounds in the hollow of the skull and fills all the spaces found between the brain and the encompassing dura mater... It seems to be a human law that the space around the spinal marrow that is filled with water increases with man's age... Hitherto anatomists have not observed this large collection of water in the spine and around the brain because of the ridiculous method usually employed for the dissection of bodies...they cut off the head with the neck...all the fluid collected around the brain and spinal marrow is at once lost... and the anatomist is misled by the appearance of empty spaces...It seems beyond all doubt that the spinal fluid, as well as that which humectifies all other cavities of the body, constantly oozes from the extremities of the smallest arteries and, finally is absorbed through very small inhaling veins, so that there is a continual state of renovation."

Further, he noted the incoagulability of CSF in health, but like urine in nephritis, which he observed some 50 years before Bright, it clouded on boiling, only in disease. This work was overlooked until Magendie reprinted it in 1827.

In this crucial work, Cotugno, an astute observer and clinician, differentiated sciatic nerve pain from arthritis of the hip, probably for the first time. The eponym Cotugno's syndrome was subsequently applied to unilateral sciatic neuralgia. He also wrote about typhus and gave a fine description of the pathology of smallpox pustules. ${ }^{5}$
Domenico Felice Antonio Cotugno (1736-1822)

Near the heel of Italy lies the town of Ruvo Pugliese, the birthplace (29 Jan 1736) of Cotugno. Most of his life he spent in Naples. His family were poor and hardship was his constant companion in his formative years. After medical training in Salerno, he worked in the University of Naples and the Ospedale degli Incurabili. Cotugno surmounted serious illness while resident at the hospital. He became an assistant at the Ospedale degli Incurabili. In 1766 he became professor of anatomy, the leading physician in Naples, and director of the Ospedale. By the age of 31 he was widely acclaimed for his excellent publications, ${ }^{6}$ including two books.

When he was only 25, in 1761, his dissertation, Aquaeductibus auris humane internae, predated the work of Hermann von Helmholtz. In it he described ${ }^{6}$ the vestibule, semicircular canals, and cochlea. He demonstrated the labyrinthine fluid, and considered mechanisms of resonance, sound transmission, and hearing. He depicted the columns in the bony spiral lamina of the cochlea known as Cotunnius' columns. His description of the nasopalatine nerve, and its role in sneezing anticipated Antonio Scarpa's work.

In 1765 he visited Rome and northern Italy, and was befriended by Morgagni. Notable success in practice led to appointment as physician to Ferdinand IV, King of Naples, accompanying his travels to Austria and Germany.

He was a dedicated doctor, but was also a student of art, architecture, Latin, and antiquities. A greatly esteemed physician, local lore was that nobody in Naples could die without a passport from him. He was renowned for his devotion to medicine and scientific investigation. He stopped teaching in 1814 but continued to attend his hospital daily. In 1818 he had a cerebral embolism that eventually caused his death on 6 October 1822 .

The generous son of a poor father, he left 100000 ducats to the Ospedale degli Incurabili.

J M S Pearce 304 Beverley Road, Anlaby, East Yorkshire HU10 7BG, UK; jmspearce@freenet.co.uk doi: 10.1136/jnnp.2003.017939

\section{References}

1 Schiller F. Domenico Cotugno. In: Webb Haymaker, Francis Schiller, eds. The founders of neurology. 2nd edn. Springfield: Charles C Thomas, 1970:19-23.

2 Willis T. Cerebri anatome. London: Martyn and Allestry, 1664, [English translation Dr Willis's practice of physick. S. Pordage. London, Dring et al 1684].

3 von Haller A. Elementa physiologiae corporis humanae, Vol IV, Lausanne, 1762, Bk X, Sec.l, pt xix. [Translation in: Clarke E, and $O^{\prime}$ Malley CD, The human brain and spinal cord:ab historical study. 2nd edn. San Francisco:Norman, 1996:727].

4 Cotugno DFA. De ischiade nervosa commentaries, Naples Fratres Simonios, 1764. Napoli and Bologna, 1761. Ex typographica Sancti Thomae Aquinatis, 1775.

5 Cotugno DFA. De sedibus variolarum syntagma, Naples, 1771, 1775. Ex typographica Sancti Thomae Aquinatis.

6 Manni E, Petrosini L. Domenico Cotugno, a pioneer in neurosciences. J Hist Neurosciences 1997;6:124-32. 